\title{
The Semantics of Parts Versus Aggregates in Data/Knowledge Modelling
}

\author{
Renate Motschnig-Pitrik \\ Department of Information Systems \\ University Vicnna \\ Liebiggasse 4, 1010 Wicn, Austria
}

\begin{abstract}
The incorporation of semantics into conceptual models has for long been a goal of the data/knowledge modelling communities. Equally, conceptual models strive for a high degrec of intuitiveness in order be belter understood by their human users. This paper aims to go one step in this dircction by introducing the part-ol relation as a special cusc of aggregation. To do so we investigate the scmantic constraints accompanying this specialization and suggest different ways of incorporating part-of semantics into data/knowledge models. Further, it is demonstrated that, in analogy with IS-A relations, part-of relations form hicrarchics (dag's) which constitute an important conceptual aid in understanding complex systems. Finally, we investigate the conditions under which the part-of relation exhibits transitive behavior which can be exploited for automated inferences facilitated by the transilivity property.

keywords: data/knowledge modelling, knowledge representation, conceptual modelling, semantic dala models, part-ol relations, objccl-oricnted databases, aggregation, transitivity, inference;
\end{abstract}

\section{$1 \quad$ Introduction}

"The whole is more than the sum of its parts"

\subsection{Motivation and Related Work}

The overall objective of inlormation systems (IS) modelling is to build models which confidently represent parts of the real world. The resulting need to model complex objects for advanced applications has lead to the development of a number of scmantic and objectoriented models that attempt to capture more of the meaning as well as the structure and bchavior of the data than traditional models $[18,30]$. In this context it is important to appreciate why it is usclul to incorporatc abstractions and additional scmantics into information system design methodologies, in particular in the early phases of the devclopment process. Davis and Bonncll $[11, \mathrm{p} .85]$ argue that it is important to incorporate appropriate abstraction mechanisms that can be used to identify suitable catcgorics with which to describe phenomena in the real world. This is motivaled by the notion that much of what is perceived in the world is generally well-structured information and that a large problem in constructing complex systems capable of intelligent bchavior is in clarifying thesc structures by using appropriate abstraction mechanisms. Furthermore [30], some of the benefits that gencrally have becn identificd as being associated with semantic models are: cconomy of cxpression, integrity maintenance, modelling llexibility, and simplifying querying. 
Whilc by far most research on cxtending IS design methodologies to capture more meaning has concentrated on the generalization/specialization abstraction and the accompanying mechanism of inheritance (c.g. $[4,22]$ ), this rescarch focuses on the part-of relation. The latter is deduced as a subcalegory of the aggregation abstraction and enriched with additional scmantics. Aggregation has becn defined as an abstraction in which a relationship between objects is considered as a higher Icvel (aggregate) object [35]. When considering the aggregate, details of the constituent objects are suppressed. An example of aggregation is depicted in figure 1-1a. Note, that the aggregatc object (c.g. room) consists of a number of arbitrary constituent objects and/or attributes. This reflects the situation most often encountered in current conceptual modelling and knowledge representation techniques. In particular, it is hardly ever distinguished between parts and other constituents making up some entity in the domain of discourse. In short, in data/knowledge modelling the part-of relation has not $(\mathrm{yct})$ becn devoted special attention.

Inspired by rescarch on parts conducted in cognitive psychology [37], we suggest to see a conceptual entity to consist of parts and, in addition, other attributes. At this point there is a strong temptation to wonder whether the distinction is not superlluous, since, attributes are parts that constitute the description of some whole. In which way, then, should there cxist attributes which are not parts? The answer is casy, but only if care is laken to distinguish between real-world concepts and their representation as data structures in some formal notation used to model these concepts: Whereas, obviously, all attributes charactcrizing some concept arc parts of the data structure modelling this concept, not all attributes are parts of the concept as such. Consider, for example, a class (or any similar structure) used to model a room. While ceiling, floor, walls, window, door are parts of the real world concept of a room (compare figure 1-lb), owner, size, and location definitely are important constituents (modellcd c.g. as attributes), but they are in no case parts of rooms. Neverthelcss, owner, size, and location are part of the class representation of rooms.

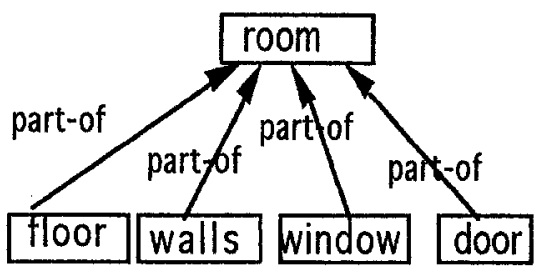

Fig. 1-1:

a) The aggregate room as an example of aggregation

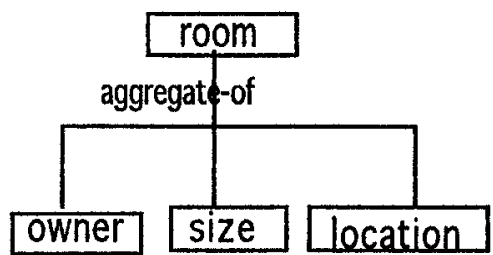

b) The composite room demonstrating the part-of relation

In this paper it is argued that the part-of relation carries specific semantics which can be cxploited to enrich conceptual models and to provide for specific inferences. Furthermore, repeated application of the part-of relation results in a hicrarchy (more preciscly a dag), herealter relerred to as partonomy. Partonomies organize concepts in terms of connections betwecn parts or components and wholes or composites.

Within the field of computer science, partonomics play an essential role for modelling systems decomposition in almost all traditional soltware development methodologies, such as SADT [33] or JSD [19] and, morc recently, object-oriented (OO) analysis and design 
(c.g. $[2,23[)$. Nevertheless, despite the importance of managing systems decomposed into scveral thousands of parts and subparts, cle. [39], the specific scmantics of part-of relations have hardly ever becn investigatcd in the context of soltware engincering. In the realm of $\mathrm{Al}$, the object-oricntcd programming language LOOPS |1/ pioncers in providing linguistic means to model compositc objects. The mechanisms for processing parts, howcver, arc 'hardwired' into the language with al most no support for incorporating additional semantics.

In particular, recent techniques for $O O$ analysis and design have rediscovered the importance of aggregation. Some techniques (such as c.g. [9, 13, 23]) even ofler specific constructs to model aggregation which often is relered to as the part-of relation. No specific semantics, however, are defined for such parts. Morcover, the examples given in the respective documentations (cxcept [23]) indicate that the general casc of aggregation is meant. In comparing $O O$ analysis methods, De Champeaux and Faure [12] nicely capture this situation and its ramifications by arguing that 'the notion of the part-of relationship is problematic when its semantics are not clarified. For instance, it is of ten unstated whether part-of is assumed to be transitive and what its bchavioral ramilications are. Should the destruction of A imply the destruction of B when B is part of A? Can an object be a subpart of more than one superpart? ... As a result of the ambiguitics surrounding part-of, an analyst should make explicit the intended semantics before using part-of.'

The situation is dilferent in the context of object-oriented databases (OODBs), most promincntly ORION [20], wherc partonomics have becn suggested as a means of modelling compositc objects and their semantics. Besides discussing the role part-of relations play in schema cvolution, Kim et al. go as far as proposing parts as a basis lor authorization and locking. The approach taken here is different. While drawing on Kim ct al.'s results regarding the semantics of parts (c. $f$. section 3.1), the emphasis is on a broader discussion of part-of semantics in the context of conceptual modelling, along with the impacts, such as inferences lacilitated by the distinction of parts from other attributes and by transitivity. This discussion is molivated by the endeavor to cxploit the semantics inherent in part-of rclations in order to allow to build models that more closely match human conceptualization. Such models, we claim, are casier to understand and to reason about.

The goals of this rescarch are to

*

*

*

*

cxamine the representational power of partonomies in their role in data/knowledge modclling, justify the importance of the part-of relationship from a cognitive point of vicw, introduce semantics of the part-of relationship and show how to incorporate them into data/knowlcdge models, open room for inference mechanisms based on the transitivity of the part-of relation.

Betorc giving a more detailed account on the points mentioned, let us view the part-of rclation as a specific case of a semantic relation and consider its representation in conceptual models. Graphical displays of entitics and relationships, such as entity-rclationship (ER) diagrams, have been popular since almost two decades for providing high Icvel representations of some parts of the real-world [10]. Their immense usclulness and conceptual aid for database design has been proven in many applications. ER diagrams have also been extended (EER, [36]) to provide specific constructs for modelling generalization/specialization relationships. The (E)ER notation serves to provide a fairly complete picture of the entitics and relationships underlying some model. Thus it often 
coexists with object browsers [15] which were invented by the object oriented programming (OOP) community as a complement to more complete representations such as (E)ER diagrams. Object browsers wcre designed to display objects (corresponding to entities) with only one or two kinds of relationship, namely subclass (or specialization) and instance-of relations. Specifically, they were not designed to display the part-of structure of objects which, as will be argued shortly, is a further fundamental organizational principle. Therefore, complementing object browsers to depict part-of relations should provide more complete cognitive maps which facilitate the understandability of the underlying models. In any case, the need to visualize complex objects situated at different levels of a partonomy has been recognized in the arca of CAD applications. In this context, Udagawa designed an elaboratc algorithm for browsing compositc objccts [38].

\subsection{Terminology}

Bcfore moving on, let us agrec upon the meaning of some fundamental terms which have been used across various ficlds in compuler science with different semantics. Talking about an object we main a symbolic structure denoting some conceptual entity. Each object has a unique object identification (oid), a name, and consists of an aggregation ol any number of attributes which collectively characterize the object. Furthermorc, an object may be associated additional semantics in which way so cver.

Attributes can either be structural, in which case they are also referred to as semantic relations, or behavioral, most prominenlly methods. We suggest to distinguish between two categories of semantics relations (sec also figure 1-2): ordinary reference relations 1 , such as works-lor or uses, and rclations which serve as basic organizational principles, such as 'is-a' $[6,4,3]$, 'instance-of' $[18,27]$, 'part-of' [40], and others [25]. To do so is not new! It is just an extension to further organizational concepts, in particular to part-of relations. Strongly simplified, an organizational principle (also called a structuring concept) must be an abstraction useful for understanding the organization or structure of complex systems and abstract from application specific relations among the entities represented in some model.

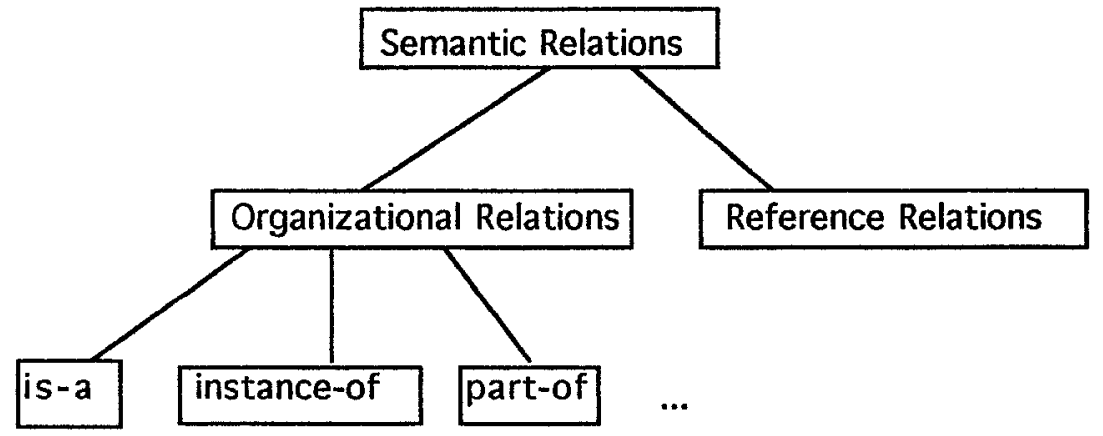

Fig. 1-2: Fragment of a taxonomy of semantic relations

1 Sometimes, for example in the ER model, attributes having clementary ranges, such as age: $1 . .100$, are distinguished from relations, such that only the former are called attributes. We do not draw this distinction and use the term attribute in a generic sense, sinee the distinction is not relevant in our context. 


\subsection{Overview of the Paper}

The incentive to superimpose part-ol semantics on aggregation [35], comes from two perspectives: cognitive psychology and data/knowledge modelling 2 . The psychologically based arguments stem from experiments assessing the importance of attributes being parts: subjects tend to describe concepts primarily in terms of parts. More on this can be found in section 2.1. The incentives from the modelling disciplines center around the incorporation of semantics being peculiar to part-of relations as well as on the cxploitation of the transitivity property of the part-of relation. Additional scmantics allow to deduce integrity constraints uscful, amongst others, in the case of updates and schema evolution. Transitivity, on the other hand, can be applied lor drawing inferences of the kind: A part-of $B$ and $B$ part-of $C$ imply A part-of $C$.

The paper is organized as follows. The next section is aimed to provide cognitive evidence on the roic parts play in the human thought process. It thus serves as a justification to consider the part-of relationship an organizational principlc. This applics in particular to notations supporting carly phases of development since such notations should be oriented toward the human user [29]. Section threc cxplores various issues resulting from distinguishing part-of relations from others taking a computer science oriented perspective. In particular, cardinality constraints and update scmantics regarding subcategorics of part-of rclations are studicd. Furthermore, the extensible CM and KR language Telos [28, 21] is uscd to cxcmplify the incorporation of part-ol scmantics into a KR notation. Scction four centers on transitivity. The taxonomy of scmantic relations suggested in [40] is used to guide a discussion on the distinction of various subcategories of part-of relations with respect to transitivity. In this context, a new break-down into subcategories is suggested, which is based on a more computer science oriented perspective and which establishes transitivity within a corc of part-of relations. A summary and indication of issues for further rescarch round up the paper.

\section{The Cognitive Perspective on Parts and Composites}

\subsection{The Role of Parts in the Human Thought Process}

There is strong psychological evidence that part-of relations associating parts or components with wholes or composites are one of the most important structuring concepts underlying the organization of human knowledge. In a controlled experiment conducted by Tversky ([37] based on work reported in [32]) subjects werc asked to list attributes of both artificial and biological kinds of objects. The attributes obtained were partitioned into two categorics: altributes being parts and not-part attributes. To distinguish between these two categories of attributes two criteria were used. The first is a dictionary definition resulting from the consultation of several dictionaries: "A part is onc of the segments or portions into which somcthing is regarded as divided; a part is less than a whole; together, parts

\footnotetext{
2 Since the concepts presented in this paper cqually apply to conceptual modelling as well as to knowledge representation, we use the term data/knowledge modelling to subsume the two ficlds. For a thorough and thoughteul distinction between CM [Brodic84] and KR [Mylopoulos90b] consult [Borgida91].
} 
constitute a whole". The second goes back to Miller and Johnson-Laird [24] who argue that a part-ol relation is often expressed in a has-a sentence frame in a similar way as is-a sentences of ten indicate texonomic relations.

The most interesting result in the context of this paper is that, in general, part attributes had a significant share: $58 \%$ of all attributes listcd for artificial objects and $42,7 \%$ of attributes ascribed to biological calcgorics werc parts. The prevalence of part lerms was most significant at the so called basic level of gencricity (excmpliticd by concepts such as bird or table). This can be cxplaincd by the fact that objects at that level mainly differ with respect to parts and that parts are associated with--and hence represent--dilferent funclionalitics. Consider for example a chair consisting of a scal which serves for sitting, a back serving for lcaning back, and of legs which scrve for moving and support. Conscquently, it are the parts of an object that are intimatcly related to the objects' behavior and that are considered perceptually most salient and lunctionally most significant.

Interpreting the prevalence of part attributes as shown in Tversky's experiment we conclude that the part-of relation is an important abstraction underlying the organization of human knowledge. The conscquence from the above for data/knowledge modelling is straightforward. If the part-ol relation has been proved to underlic our internal representation, it will be uscful to cmbody it into formal represcntations which aim to support understandability. In particular, the close relation between the parts of an object and aspects of this objects behavior underline the importance of parts in OO approaches, which charactcrizc objects via their structure as well as bchavior. A complementary issuc is to which degrec an organizational principle such as the part-ol relation proves useful for the representation and reasoning in formal models. This aspect will be subject to investigation in the next section alter discussing the relevance of our findings when applied to graphical representations.

\subsection{The Representational Account of part-of Relations}

In the following let us approach the representational impact of part-of relations from a pragmatic side and, for this purpose, consider IS design notations which have been proved to be uscful tools for conceptualization. Pcrhaps the most broadly used high level graphic notation is the ER diagram [10]. It confidently represents cntitics (concepts) and relationships holding betwecn thesc concepts. While it is perfectly helplul in modelling small systems, it has been observed that (the original) ER diagrams lack abstraction mechanisms to make them usel ul to represent the structure of very large systems. In this respect, concept taxonomies and browsers have becn apprecialcd. In a similar vein, the partof relation could be used to extract partonomics to be supported by browsers on the part-ol relation.

To demonstrate the situation, ligures 2-1 and 2-2 show, respectively, an ER diagram and a partonomy cxtracted from the ER diagram and complemented by further parts. Figure 2-2 displays the partonomy while abstracting from ordinary reference relations. The figures scrve to provide a juxlaposition of the semantic relations of aggregation versus part-ol. The reader will agrec that figure 2-2 is less informative than figure $2-1$ but that it shows the part structurc of the underlying application much more transparently. Not to be misunderstood, the loregoing discussion in no case should be interpreted as an argument against aggregation which, by the way, is the abstraction underlying the very cssential construct of a chunk or 
modulc. The juxtaposition should just serve to demonstrate the complementarity of aggregation and part-whole abstaction and to help to arguc in favour of vicwing partonomics as a uscliul complement or specialization of aggregatcs. Even more importantly, the two ligures should help to show the importance of distinguishing aggregation from part-whole abstraction. Whercas the former is well recognized across different lields of computer science, the latter has been overshadowed by aggregation, except for a few cxceptions. These stem most notably from OODB's [20], CAD applications and, to a certain degrec, from the modelling of complex objects in Al programming languages such as LOOPS [1].

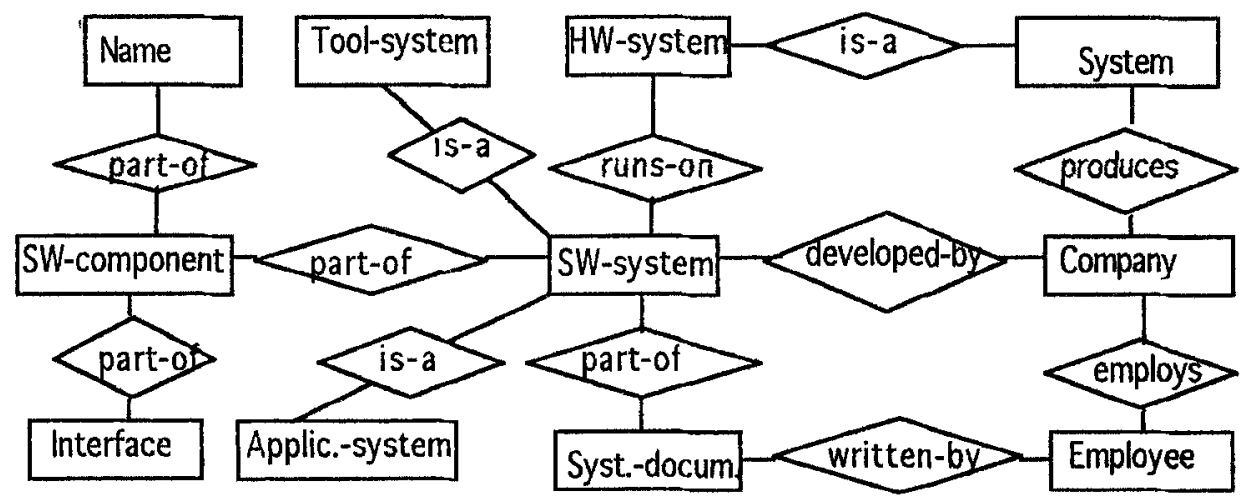

Fig. 2-1: ER diagram displaying entities and relationships in the context of a software system

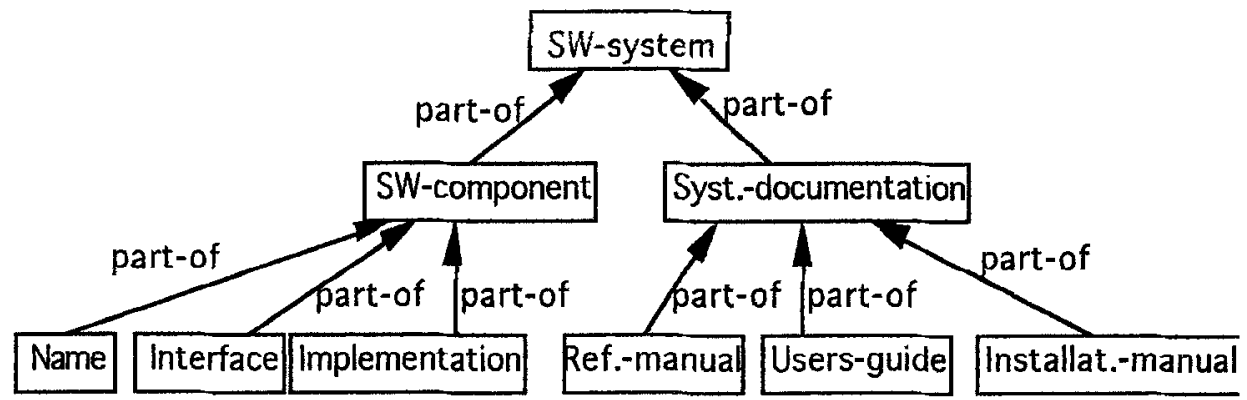

Fig. 2-2: Partonomy of a softwarc system

Summarizing, we suggest that the part-of relation descrves specific support in notations for data/knowledge modelling, in addition to the support of the aggregation abstraction. This is due to the cognitive salience of parts as well as to the representational benclits resulting from partonomies. Further note, that inissing support of parts has been experienced and documented to be a scrious drawback in the use of hypertext systems such as Notceards [16]. 


\section{Implications for Conceptual Modelling and Knowledge Representation}

\subsection{Exclusive Versus Shared and Dependent Versus Independent Parts}

As computer scientists we are most prominently interested in the leasibility and in the benefits of incorporating semantic concepts into formal models. Therefore, this section is concerned with the question which additional scmantics can be altributcd to part-whole relations, how these semanties can be incorporaled into modclling languages, and what implications this has with respect to updates of the knowledge/database and with respect to the support of inferences.

Subsection 3.1 almost completely borrows from [20]. In particular, the extremely useful--as we believe--categorization of parts into cxclusive versus shared and dependent versus independent oncs has first becn suggested by Kim et al. $120 \mid$ in the context of modelling composite objects in the OODB ORION. The underiying mechanisms, though, will be summarized in the following in order to make the paper scll-contained. Also, to allow for the discussion of conscquences, such as the implications on the formulation of cardinality constraints and on inferences facilitated by exploiting transitivity.

Kim et al. observed that while it is common for objects in OODB's to reference any number of other objects, no specific scmantics are captured by such reference links. The authors therefore suggest to supcrimpose the is-part-of relation on nested objects such, that an object may be part of another object. A set of component objects which form a single conceptual cntity (a whole) is then referred to as composite object and the links connecting the components with this object are called composite (or, in our terminology part-of) links. Importanly, the model allows to specify for each composite link whether the relerence is exclusive, i.c. the component cxclusively bclongs to the compositc, or shared, mcaning that the component may possibly be part-ol several composites. Further, a part-of link can be delined to be cither dependent, which means that the existence of the component depends on the cxistence of the compositc, or independent, i.c. having cxistence irrespectively of the composite. On the whole, four types of composites result from combining the two features.

Consider, lor example the reference in figure part-of paper. This reference should be modeled as shared and independent in order to obtain the semantics that cach figure may appear in more that one paper and may cxist independently of any paper. (This can be implemented, for example, by kecping ligures on a separate file.) The situation is different with the scmantics of part-of in a sentence such as brain part-of person, in which brain would be characterized as exclusive and dependent. This is because one brain cannot be part of more than one person and its lifetime depends on the lifetime of the person. As another example imagine a situation as cxpressed in engine part-of car. In this case we may want to model the part-of link as exclusive but independent, to achicve the semantics that, at one point in time, an engine can be part-of at most one car and can cxist independently of any car.

Kim et al. formalize the semantics of the different types of part-of references in terms of constraints which must hold if objects are created or delcted. To provide an example, consider the deletion of an object O': 
If there cxists a dependent and exclusive part-of reference from $O^{\prime}$ to another object $O$ (i.c., $O$ part-ol ' $O^{\prime}$ ), then it holds that the delction of $\mathrm{O}^{\prime}$ implies the deletion of $O$. In case that the reference is independent, however, the deletion of $O^{\prime}$ does not imply the delction of $\mathrm{O}$.

In a similar vein, specific conditions on some attribute A must hold, if one wishes to make an object $O$ part-ol' $O^{\prime}$ through this altributc. Furthermore, the semantics of composite objects are formalized by stating lopology rules, such as the following:

If an object $O$ has an independent exclusive part-of reference to it, then it cannot have a dependent exclusive reference from another object, and vice versa.

The syntax for attribute specification (within class definitions) used in ORION to support the full semantics of part-ol links is the following:

symax for attribute definition:

(attributeName

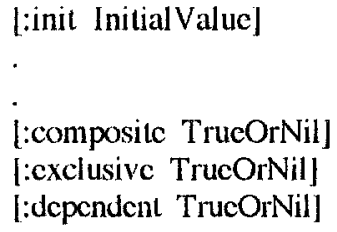

example: class Paper with altribute figures:

$\begin{array}{ll}\text { ligures } & \text { :init ... } \\ & \cdot \\ & : \text { composite true } \\ & \text { :exclusive nil } \\ & \text { :dependent nil }\end{array}$

\subsection{Cardinality Constraints Associated with part-of Links}

In conceptual knowledge/data modelling it is appreciated to annotate relationships (links, slots) with cardinality bounds. Thus ligure $3-1$ will be interpreted as follows:

ENGINE $\frac{\text { exclusive, independent }}{(0,1) \quad \text { part-of }(1,1) \text { CAR }}$

(a)

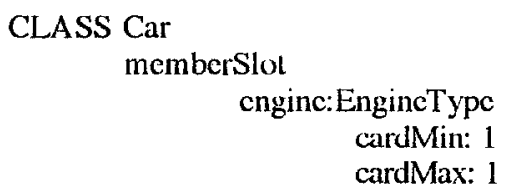

(b)

Fig. 3-1: Cardinality constraints expressed in an ER diagram- (a) and a frame based notation (b) 
Each engine is part-of at lcast zcro and, at one point in time, at most one car. Similarly, a (ordinary) car has, at onc point in timc, at least onc and at most one (i.c. exactly onc) cnginc. In a lrame bascd, object-oricnted notation the lormer constraint is cxpressed as shown in ligure $3-\mathrm{lb}$.

Minimality and maximality constraints on the various types of part-ol relations can easily be derived from the topology rules and constraints given in [20]. Figure 3-2 depicts the results and furthcrmore provides cxamples for cach type (combination of 'lcatures) of part-of relation. While the first and last cxample in ligure 3-2 have already becn described above, the second and third phrase remain to be explained. The component paper, in paper part-of journal is specificd to be exclusive and independent. This is because we do not want the same paper to appear in more than one journal and wish to grant to cach paper an existence which is independent of that of the journal containing the paper. Next, consider the phrase subprogram part-of program-library. In this casc the desircd scmantics arc such that on the onc hand the subprogram shall be allowed to be shared (reused) among several software products but, on the other hand, should cease to exist upon the deletion of the programlibrary, given the subprogram is no longer referenced as being part of some software product. Hence we assign the calegories shared and dependent. In all the examples note the distinction between the type- and the token (instance) level: all the semantic constraints associated with individual catcgorics of part-ol relations are given at the type (or class) level, such that they apply to all objects (tokens) being instances of the corresponding types (classes).

From figure 3-2 it follows that part-of links which are exclusive imply a one as the maximum cardinality on the component object (left hand) side, whilc, obviously, shared part-of links allow for a maximum cardinality of arbitrary many ('*') on the Iclt hand side. Similarly, dependent part-ol links call for a one as minimum cardinality since, by definition, the object they are part-of must exist, whercas the minimum cardinality of independent part-of links is zero. Notc, that no cardinality constraints can be deduced for the inverse relation has-part (compare the irregularity of cardinality bounds on the right hand side). This is because, in gencral, onc cannot deduce that some composite object $O$ has at most one component $\mathrm{C}$ of one type from the lact that $\mathrm{C}$ is an exclusive component of $\mathrm{O}$. If, for example, one cngine (at one point in time) can be part of one car only, one might well cnvisage a car having a sccond (c.g. spare) engine as its part. Hence the minimum and maximum cardinalities on the right hand sides are intended as examples only, with no claim for generality. Note, however, that also the inverse relationship to part-of, namely has-part, can be scmantically cnriched by using the features exclusive/shared and dependentindependent. 

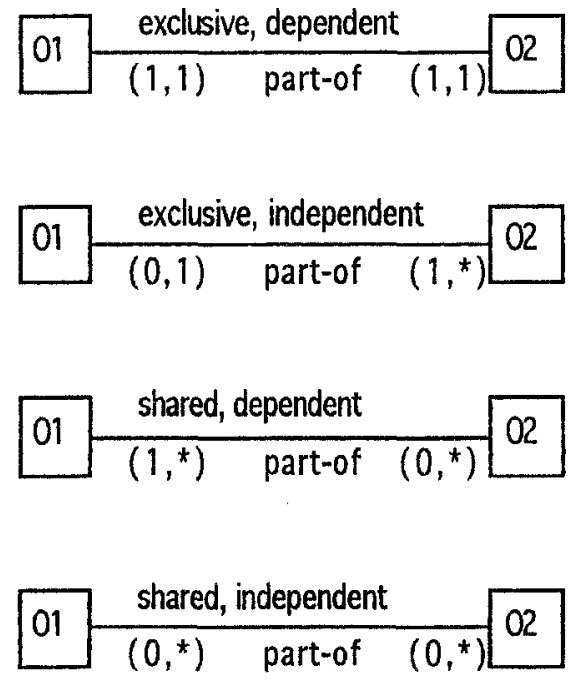

e.g. brain part-of person

e.g. paper part-of journal

e.g. subprogram part-of program-library

Fig. 3-2: Cardinality constraints depending on the type of part-of relation plus examples

\subsection{The Knowledge Representation Perspective}

Surprisingly, lrame based and object-oriented KR languages, in general, do not support partof rclations, although part-of links used to play an important role in scmantic networks (sce, for cxample [5]. Most probably the disappcarance of part-of links is attributable to the fact that they were generalized to become slots, which encode all kinds of references including references to parts. While the aggregation of slots to describe concepts or objects has proven to be an cxtremely uscful mechanism, part-of scmantics, in general, are not captured in such descriptions. To reconcile the notion of slots (or attributes) with that of additional part-of semantics, Ict us discuss in which way a slot specification can be extended to capture part-of scmantics. Note, that KR languages designed for cxtensibility arc particularly well suited for such an entcrprisc. For this reason we chose Telos [28] to demonstrate the necessary build-ons. In the scquel, only a simplificd version of Tclos will be used. Also, only the features necessary to understand the incorporation of part-of semantics will be described. For Turther details on Telos and on a formal account of its syntax and scmantics consult $[21,28]$.

Telos explicitly supports the following three structuring concepts (compare also figure 3-4):

$$
\begin{array}{lll}
\text { classification } & \text { via } & \text { keyword IN followed by list of classes } \\
\text { generalization } & \text { via } & \text { keyword ISA followed by list of classes } \\
\text { aggregation } & \text { via } & \text { kcyword WITH followed by a list of attributes grouped } \\
\text { into altribute catcgories; } &
\end{array}
$$

Specifically, the WITH clause serves to associate not only propertics but also assertions to classes. One distinguishing feature of Telos is its treatment of attributes as first-class citizens, i.c. objects which have their own identificrs and can be organized along any of the structuring dimensions mentioned. The attribute mechanism of Telos, in particular the 
handling of attributes as full objects and the capability of defining assertions as attribules, combined with a stratificd multi-level classification lattice allow Telos to be adapled to new modelling necds $[28,27]$. In the sequel, this will be demonstrated by using Telos to capture the scmantics of attributes being parts belonging to any of the four types specilied in section 3.1.

To accomplish this, we first specily three attribute melaclasses, namcly Part, ExclusivePart and DependentPart, which, respeclively, capture the semantics of the various types of parts as depicted in ligure 3-3a-c. Interpreting the ligurc in some more detail, the attribute melaclass Part as such does not include any integrity constraints, rellecting the semantics of shared and independent parts. Nevertheless, the Part metaclass plays an important role in allowing to distinguish and to group part-attributes. Moreover, it serves as the common parent of ExclusivePart and DependentPart in the ISA hicrarchy. The integrity constraint in ExclusivePart (comparc figurc 3-3b) states that, at any given timc, an object $O$ being an cxclusive part of a composite object $\mathrm{O}^{\prime}$ cannot be part of yct another composite object. (In Telos terms this is expressed such that part-of links having the same destination--the part, denoted by $t o(x)$--must have the same source--from $(x)$.) Similarly, the integrity constraint in DependentPart says that the lifetime of a dependent part, say $O$, ecases if the lifetime of the composite on which $\mathrm{O}$ depends comes to an end, and $\mathrm{O}$ is no longer referenced as being part of any other composite objecl.

As can be seen from the figure, attribute classes sirongly resemble ordinary classes. The main difference is that the former more heavily rely on assertions to formulate constraints instead on altributes specifying relationships. In order to associate the scmantics defined in attribute metaclasses with an "ordinary" object's altribules, the melaclass of onc's choice is instantiated to bccome an attributc class or, synonymously, catcgory in some class $\mathrm{C}$. Further, an attribute of one's choice is associated with the corresponding attribute category by listing it under that calegory (compare figure 3-4). As an example consider the attribute figures listed under the calcgory part in figure 3-4. As another example consider the allribute footnotes, which is associated threc catcgorics part, cxclusive, and dependent, in order to express that lootnotes exclusively belong to one paper and ccase to be of any interest when the paper is no longer stored. The latter cxample demonstrales in which way attributes may be associated with more than one category. In this case the constraints stemming from the corresponding attribute metaclasses listed in the header are combined.

Note that, using attribute categories, a part attribute is by default shared and independent such that additional constraints can be imposcd on it by listing further attributc catcgorics. Note further, that attribute metaclasses in Telos are highly modular and reusable and not particularly tied to part-of semantics. One could easily envisage to specily objects which depend on other objects and yet are not their parts.

So far we have argued that part-of semantics can be incorporated into KR languages via the specification of attribute mctaclasses, as in Tclos. But also languages with no support of altribute classes can be cxtcnded to caplure part-of scmantics if they provide for (uscr definable) annotations. Annotations are associated with slots and serve to capture some of the semantics of the slot to which they arc associated. Typical examples of built-in annotations are cardinality or type constraints on slot fillers (see, for example, figure 3-1b) [14]. Since most of the more advanced KR languages allow users to specily annotations (most often using some host language such as LISP), part-of scmantics can be capturcd by defining annotations such as part, cxclusive, and dependent. Slots then are annotated with 
any combination of the three annotations in a similar way as attributes are associated attributc classes. Note, however, that the annotation approach docs not cncourage the tcxlual grouping of slots carrying the same scmantics as has been the casc with attributc classes.

TELL CLASS Part $/ *$ shared, independent parts */

IN MI_Class, AltributcClass

END

TELL CLASS ExclusivePart

IN M1_Class, AtributcClass

ISA Part

WITH

integrityConstraint

cxclConstr: $\$$ (Forall $x, y /$ Attribute) (Forall $z, z^{\prime} /$ AltributeClass)

(Forall $\mathrm{t}$ Timelnterval)

( $\left(z\right.$ in ExclusivePart) and ( $z^{\prime}$ in Part) and $(x$ in $z)$ and $\left(y\right.$ in $\left.z^{\prime}\right)$ and

END $\operatorname{to}(x)=\operatorname{to}(y)=\Rightarrow$ from $(x)=$ from $(y))$ [over l] $\$$

TELL CLASS DependentPart

IN M1_Class, AtributcClass

ISA Part

WITH

integrityConstraint

dpdiConstr: $\$$ (Forall $x / A t$ tribute) (Forall $z, z^{\prime} /$ AltributcClass) (Exists y/Attributc)

(Forall UTimcInterval)

( ( $(z$ in DependentPart $)$ and $(x$ in $z)=\Rightarrow[$ when $(\operatorname{to}(x))$ during when $($ from $(x))\rfloor)$

or

$\left((z\right.$ in Part $)$ and $\left(y\right.$ in $\left.z^{\prime}\right)$ and $\operatorname{to}(x)=$ to $(y)$ and not $(\operatorname{from}(x)=$ from $\left.\left.(y))\right)\right)$

[over l] \$

END

Hig. 3-3a-c: Specilication of part-scmantics via attributc metaclasses in Telos.

TELL CLASS Paper

IN S_Class $\quad l *$ Simple Class $* /$

ISA Document

WITH

altributc

author: Name

part $\quad f^{*}$ i.c. shared and independent part */

ligures: Imagc

part, cxelusivePart, dependentPart

footnotcs: String

\section{END Paper}

Fig. 3-4: Example showing the association of various attribute catcgorics to attributes 


\subsection{Further Categories of Parts and their Semantics}

An analogous approach as that described in the previous subsections can be taken to define yet further calegories of part-of relationships and associate with them specific samantics. For cxample, a part can be optional, such as 'mousc part-ol PC' or essential, such as 'processor part-of PC' carrying the following semantics. Whereas the delction of an optional part will leave the corresponding composite unaffected, the delction of an cssential part will cause the deletion of 'its' compositc.

Although all examples of parts given so far have concerned data entities, the notion of parts cqually applics to aclivitics, which arc often cncountered as separate modelling primitives in requirements modelling techniques. Considering activities, parts can be conceived as partial activities or, in other words, as phases of some superordinate activity. Additional semantics can be associated with phases by formalizing the common sense fact that cach phase must lake place within a time interval which is fully contained in the time interval of the superordinate activity. A sample specification of phase-semantics in Telos is given in figure 3-5. A lurther specialization of part scmantics can be undertaken by delining special phases, such as initial, intermediate and final ones: an initial phase of an activity $A$ is defined to costart with $\mathrm{A}$, an intermediate phase must start later and tcrminate sooner than $A$, and a final phase must cnd simultancously with A. As an cxample for the application of phase categories consider a (meta)model of the software process. Such a model could declaratively describe that, al a gross level, soltware development is split into three phases: an initial phase of requircments analysis, an intermediatc phasc of design, and a final phase of coding.

TELL CLASS Phasc

IN M1_Class, AttributcClass

ISA Part

WTTH

intcgrityConstraint

z/AltributeClass)

phaseConstr: $\$$ (Forall al,a2/Activity) (Forall $\mathrm{x} /$ Attribute) (Forall

(Forall $\mathrm{t1}, \mathrm{t} 2 /$ TimcIntcrvall)

$((z$ in Phase) and $(x$ in $z)$ and (from $(x)=a 1)$ and $(t o(x)=a 2)$ and

END

[t1 during 12$]$ and [ $[$ rom $(x)$ during 11$]) \Rightarrow[\operatorname{lo}(x)$ over 12$] \$$

Fig. 3-5: Specification of the semantics of phases in Telos.

\section{Transitivity}

KR languages strive for powerful inlerence mechanisms allowing them to deduce new knowledge from existing one without human intervention. One familiar source of inference is the law of transitivity which holds for example for is-a relations and largcly contributcs to the power of is-a inheritance. Inheritance, in general, does not hold for part-of relations: the attribute numberOrWhecls attached to the class Car docs not make scnse to be attached to the Class Engine which is part-of Car. Nevertheless, intuitively, we expect the part-of rclation to be transitive. Knowing, for cxample, that a processor is part-of a $\mathrm{PC}$ and a $\mathrm{PC}$ is 
part of a computer system, it scems plausible to conclude that a processor is part of a computer systcm. Neverthcless, on investigating part-ol" relationships Winston ct al. [40] have found that it is not in all cascs that the part-ol relation is transitive. Consider, for example, the syllogism:

the conductor's arm is part-of the conductor, the conductor is part-of the orchestra, \# the conductor's arm is part-ol the orchestra.

This transitive combination sounds very odd at best! The strange bchavior around part-of transitivity has led Winston $\mathrm{cl}$ al. 10 systematically investigate the transitivity of part-of relations. The authors found oul that the part-of relation can be partitioned into six semantic categories, which are summarized and demonstrated by examples as follows:

category of part-of relation:

$\begin{array}{ll}* & \text { component/object } \\ * & \text { member/collection } \\ * & \text { portion/mass } \\ * & \text { stufl/objecl } \\ * & \text { fcalurc/activity } \\ * & \text { place/area }\end{array}$

example:

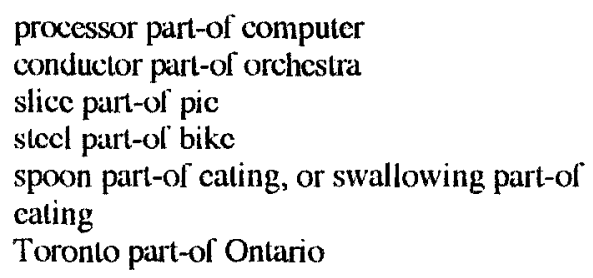

It is argued that transitivity always holds when semantic relations of the same calegory are combined. The authors further present examples to show that the combination of part-of relations stcmming from different scmantic calcgories lcads to unscnsical or at least highly questionable results. Critical cxamination of these examples, however, leads us to propose that only some of them $\mathrm{sccm}$ to prove the intransitivity of the part-of relation (in the case that the two constituents of the premise cach stem from different categories). Other examples, conversely, at worst sound a bit strange but in no case wrong. This is becausc, as we conjeclure, in nalural language one would use a more specialized and hence more suitable term instead of using part-of. As an cxample consider one of the examples classilied as a failure of transitivity in [40]:

The refrigerator is part-of the kitchen, the kitchen is part-of the house,

$\rightarrow$ ? the refrigcrator is part-or the housc.

If explaincd as: the refrigerator is part of the equipment of the housc, or, in the context of sclling the house and leaving the refrigerator in it such that the fridge constitutes one item in assessing the composite value of the house there does not secm anything wrong or even strange about the transitive conclusion.

It is only fair to mention that Winston's taxonomy of part-of relations has been designed not to cnsurc transitivity, but, in the first place, to distinguish between semantic subcalcgorics of part-of relations on the basis of similarity. Thus relations belonging to the same subcalegory are morc similar in terms of sharing values for three features called relational elements. Morc preciscly, two part-of relations belong to the same catcgory if and only if they share values for the relational elements functionality, separability and 
homogeneity [40]. Storcy [34] gives excellent account on how the similarity among part-of relations belonging to the same subcatcgory can be cxploited in conceptual database design to add semantics to the design and hence to build models which more faithfully capture the intended subject matter. Note, however, that, in general, cardinality constraints do not automatically follow from membership in some subcatcgory, as we have observed to be the case with distinguishing cxclusive/shared and dependent/independent types of part-of relations. We conclude that Winston's subcategories and Kim's features provide complementary mcans to enrich data/knowledge modelling by supplying additional semantics of part-of relations.

Kecping transitivity in mind, a closer look--and, admittedly, some conceptual modelling bias--at the examples and results in [40] leads us to suggest a different partitioning of partof relations on top of that proposed by Winston ct al. . The strategy thercby is to group those part-ol relation catcgories which, when combined by transitivity, lead to acceptable results, while scparating those which lead to crroncous implications. The reader will sec soon that, intcrestingly, the results of this separation process are completely in line with the more computer science based conceptual modelling perspective. The following is intended to document the process of extracting those semantic relations from the taxonomy of Winston ct al. which impede transitivity across subcalcgorics.

Many semantic models such as SDM [17] or ACM/PCM [7] provide a specific type constructor, called grouping or association, to model the relationship between members and a collection. Thus, in semantic modelling, member/collection relationships are scen to constitute a specific structuring concept rather than a subcalegory of part-of relations, as suggested in [40]. In fact, we obscrved that transitive combinations including cxactly onc of the premises from the member/collection calcgory are those that sound worst (or most funny, if you like). The reader will remember the example of this combination given with the conductor's arm being part of the orchestra. Clearly, the conductor in more appropriately a member of the orchestra, hence the odd conclusion above.

The situation is somewhat different with object/stuff relations, which are the next candidates to be climinatcd as a subcatcgory from a more restricied the part-of taxonomy, since they destroy transitivity. Object/stuff relations, we suggest, shall be dcalt with in a way akin to other special purpose relations such as works for in employec works for company. They secm to be situated on the very end of part-of relations anyway since the specific purpose natural language term made-of fits much better than part-of to describe the situation. A bike is clearly made of aluminium or made of steel rather than aluminium being part-of the bike according to the definition of parts given in section 2.1. Furthermorc, the substitutability of part-of by the verb phrase made-of is a simple critcrion to sort out object/stuff relations from what we arc going to call the core part-of relations. Finally, a minor constraint on the feature/activity category is nccessary to ascertain the transitivity of the remaining corc partof relations. We constrain the fealure constituent in the feature/activity category to mean only a phase or a subactivity, such as starting is part-of driving (phase), or, breathing is parl-of jogging. Spccifically, phrases such as running-shocs are part-of jogging, or, a spoon is part-of cating, do not qualify as proper part-ol relationships, since shocs or a spoon are neither phases nor subactivities!

Excluding situations as the above from the core part-of relations does little harm, since, firstly, they are casy to be distinguished and, sccondly, they can be modelled as any other special purpose relerence relation. Again, we give a comparison with natural language: one 
is more inclincd to say, for instance, running-shoes are used lor jogging and a spoon is used for cating than to consider the instruments part of the activity itself. Constraining the lcalure to be a phase or subactivity, or--in syntactic terms--a verb, is particularly uselul for assuring transitivity since it implicilly constraints the legal combinations of premises to imply conclusions via transitivity: This is becausc activities are necessarily verb phrases, as are phases and subactivities. Conscquently, it is on syntactic grounds already that the constrained feature/activity category, also referred to as verb-feature/activity catcgory, is scparaled from all the other calcgorics which happen to relate noun constituents.

In brief, if the scmantic categories member/collection, stulf/object, and noun-feature/activity are modelled by means other than part scmantics, i.c. by relicrence relations, we have obscrved that the remaining part-ol relation catcgorics, making up the core part-of relations, exhibit transitive behavior if combined in any arbitrary way. Explicilly, the following catcgorics are defincd as belonging to the core part-of relations:

$\begin{array}{ll}* & \text { componcnl/object } \\ * & \text { portion/mass } \\ * & \text { verb-leaturc/activity } \\ * & \text { placc/arca. }\end{array}$

In order to argue in favor of the transitivity of the core part-of relations two issues remain to be shown, namcly that the verb-lcaturc/activity catcgory is transitive in itsclf (since it can't be combined with the other catcgorics on syntactic grounds) and that any two-place variation of the remaining three catcgories from the core part-of relations is transitive. Although we are fully aware of the fact that positive cxamples can, at their best, test, but never verify a hypothesis, the interested reader is referred to the appendix for examples of all variations. These examples seem to indicate the transitivity of the core part-of relations. In any casc, further cmpirical investigation is neccssary to gain confidence in the preliminary results presented above.

Summarizing, the considerations in gaining or preserving transitivily have led us to define corc part-of relations. These constitute a more constraincd class of part-of relations than the join of the six subcategorics as proposed by [40]. In this context we have argued that inferences resulting from transitivity can salely be drawn within the core part-of relations. In particular, we have shown that member/collection relationships are not transitive and hence should be dealt with scparately from part of relations. This conclusion smoothly fits the CM perspective, which traditionally has suggested the concept of grouping or association to model member/collcction relations.

\section{$5 \quad$ Summary and Issues for Further Research}

We have argued on the prominent role parts play in human cognition and pointed to the advantages of providing (formal) represcntations with a high degrec of correspondence with (natural) cognitive maps. Hence, we have investigated the idea of distinguishing parts from other attributes in the field of data/knowledge modelling. In particular, three main benclits were identificd to result from the distinction of parts from other attributes: 
* the incorporation of additional semantics lads to models that more closely match (some aspects of) the rcal world;

* the representation of partonomies provides a conceptual aid since partonomies can be secn as partial cognitive maps, much in the flavor of taxonomies but orthogonal to them;

* the exploitation of the transilivity property of part-of relations gives room for powerful automated inferences.

In order to realize these bencfits, we have investigated various ways of incorporating the semantics of parts into dala/knowledge models. Thereby cxicnsible languages were found to be particularly well suitcd for this purpose. Although we do not doubt that the specific role parts play in human cognition should be given account in artificial representations, future rescarch is still necessary to

* confirm or to adjust our findings on transitivity;

* to find more precisc and yel straightforward (easy to apply) criteria on what parts are, in areas such as social systems, for example organizations, or social cvents, such as the organization of a conference. In these systems the distinction of parts is by far less obvious than c.g. in CAD models or CASE applications (compare also figure 22).

Further, following the research presented in [37], it would be worthwhile to investigate object-oriented analysis design methodologies (for cxample [2]) which distinguish a base level of classification to contaminatc part attributes at the cost of super- and subordinatc levels to concentrate of functional features and specializations of parts, respectively. Finally, our rescarch is directed towards the investigation of further organizational principles [26], such as perspectives, in order to cxamine their cognitive and representational account as well as to determine their semantic properties.

Acknowledgements: Special thanks to Alex Borgida, John Mylopoulos, and Veda Storey for their insightful discussions and comments on an carlier dralt of this paper.

\section{References}

1. Bobrow, D.G., Stcfik, M.J., "The LOOPS Manual"; Xerox Corporation, Palo Alto, Deccmber 1983.

2. Booch G.: "Object-Oriented Design with Applications"; Benjamin/Cummings, 1991.

3. Borgida A.: "Knowledge Representation, Semantic Modeling: Similarities and Differences"; H. Kangassalo (cditor), Entity-Rclation Approach: The Core of Conceptual Modelling, Elsevier Science Publishers B. V. (North Holland), 1991.

4. Borgida A., Mylopoulos J., Wong H.K.T.: "Generalization/Specialization as a Basis for Software Spccification"; in: "On Conceptual Modclling"; Brodie M.L., Mylopoulos J., Schmidt J.W., cditors, Springer-Vcrlag 1984. 
5. Brachman R.: "On the Epistcmological Status of Semantic Networks", in Associative Nelworks: Representation and Use of Knowledge by Compulers, Findler, N., V., (cd.), New York, Acadcmic Press, 1979.

6. Brachman R.J.: "What Is-a Is and Isn't: An Analysis of Taxonomic Links in Scmantic Networks"; IEEE Computer, October 1983.

7. Brodic, M., L., Silva, E., "Active and Passive Component Modelling: ACM/PCM"; Information Systems Design Mcthodologies: A Comparative Revicw, Olle, Sol, Vcrrijn-Stuart, cd., North Holland Publ. Comp., 1982.

8. Brodic M.L., Mylopoulos J., Schmidt J.W., cditors: "On Conccptual Modelling"; Springer, 1984.

9. Coad P., Yourdon E.: "Object-Oriented Analysis", Yourdon Press Prentice Hall, Englewood Cliffs, NJ, 1990.

10. Chen P.P.S., "The Entily-Relationship Model - Towards a Unified View of Data"; ACM TODS, Vol.1, No.1, 9-36, 1976.

11. Davis J., P., Bonncll R., D.: "A Framework for Constructing Visual Knowledge Represcntation Specilications in Acquiring Organizational Knowledge", in Knowledge Acquisition, Vol.3, No 1, p.79-115, March 1991.

12. De Champeaux D., Faure P.: "A Comparative Study of Object-Oriented Analysis Mcthods", Journal of Object-Oriented Programming, p. 21-33, March/April 1992.

13. Embley D., W., Kurtz B., D., Woodfield S., N.: "Object-Oriented Systems Analysis A Model-Driven Approach", Yourdon Press, Englcwood Clilrs, NJ, 1992.

14. Fikes R.E., Kehler T.P.: "The Role of Frame-Based Representation in Reasoning"; in: CACM, Seplember 1985.

15. Goldberg, A. and Robson, D., Smalltalk-80: The Language and its lmplementation, Addison-Weslcy, 1983.

16. Halasz, F., G., "Reflections on Nolecards: Seven Issues for the Next Generation of Hypcrmedia Systems"; CACM, Vol.31, No.7, 836-852, July 1988.

17. Hammer, M., Mc Leod, D., "Database Description with SDM: A Semantic Database Modcl"; ACM TODS, Vol.6, No.3, 351-386, Sepl. 1981.

18. Hull, R. and King, R., "Semantic Database Modelling: Survey, Applications and Rescarch Issues", ACM Compuling Surveys 19(3), September 1987.

19. Jackson, M., "System Develpoment"; Prentice Hall, 1982.

20. Kim, W., Bertino, E., Garza, J., F., "Composite Objects Revisited"; OOPSLA 89', 337-347, 1989. 
21. Koubarakis, M., Mylopoulos, J., Stanlcy, M., Borgida, A., "Telos: Fcatures and Formalization", KRR-TR-89-4, University of Toronto, Fcb. 1989.

22. Lenzerini M., Nardi D., Simi M. (ed.): "Inheritance Hierarchies in Knowledge Represcntation and Programming Languages", John Wilcy \& Sons, 1991.

23. Martin J., Odell J.: "Object-Orientcd Analysis and Design", Prenticc Hall, Englewood Cliffs, NJ, 1992.

24. Miller, G., A., Johnson-Laird P., N., Language and Perception, Cambridge, MA: Harvard Universily Press, 1976.

25. Motschnig-Pitrik R., "A Framework for the Support of a Common Structural Level for Software, Databasc-, and Knowledge Based Systems"; The Journal of Systems and Soltwarc, North Holland, Vol.12, No. 12, 157-165, 1990.

26. Motschnig-Pitrik R., "Toward a Common Structural Lcvel for Software, Database-, and Knowledge Bascd Systcms"; Applied Artificial Intelligence, An Im.. Journal, Hemispherc Publ., Vol.3, No.4, 405-426, 1991.

27. Motschnig-Pitrik R., Mylopoulos, J., "Classes and Instances"; Int. Journal on Intelligent and Cooperative Information Systems, Vol.1, No.1, 1992.

28. Mylopoulos, J., Borgida, A., Jarke, M. and Koubarakis, M., "Telos: Representing Knowlcdge About Information Systems", ACM Transactions on Information Systems, (to appcar).

29. Mylopoulos, J., "Object-Orientation and Knowledge Representation", in Mecrsman, R. and Kent W. (cds.) Proccedings of the IFIP-TC 2 Working Conference on Databasc Scmantics: Object-Oricnted Databascs -- Analysis, Design and Construction, Windermere UK, July 1990.

30. Pcckham J., Maryanski F.: "Semantic Data Models", ACM Computing Surveys, Vol.20, No.3, p.153-189, Scplcmber 1988.

31. Pitrik, R., "Structuring Principles in the Design of Software Systems", in: Advances in Compuler Science; G. Lasker, cd., University of Windsor, Canada, $1989 .$.

32. Rosch, E., "On the Internal Structure of Pcrceptual and Semantic Categories", in T. E. Moore (cd.), Cognitive Development in the Acquisition of Language, Ncw York: Academic Prcss, 1973.

33. Ross, D.T., "Structurcd Analysis (SA): A Languagc for Communicating Idcas"; IEEE TSE Vol. SE-3, No.1, 1977.

34. Storcy, V., "Understanding Semantic Rclationships"; Working Paper, University of Rochester, NY, January 1992; 10 appear in the Journal on Very Large Data Bascs. 
35. Smith J., Smith D.: "Data Abstractions: Aggrcgation and Gencralization", TODS, Vol.2, No.2, p. 105-133, Junc 1986.

36. Teorcy, T., J., Yang, D., Fry, J., P., "A Logical Design Methodology for Relational Databascs Using the Extcnded Entity-Relationship Modcl"; ACM Computing Surveys, Vol.18, No.2, 197-222, Junc 1986.

37. Tversky B., Hemenway K.,: "Objects, Parts, and Catcgories"; Journal of Experimental Psychology: General, Vol.113, No.2, 169-191, Junc 1984.

38. Ugagawa, Y., "Implementation and Evaluation of a Browsing Algorihm for Design Applications"; Proc. of the 7 th Int. Conf. on Data Engincering, IEEE, 70-78, Kobc, Japan, April 8 - 12, 1991.

39. Wand Y., Weber R.: "A Unificd Model of Software and Data Decomposition", Working Paper, Fac. of Commerce and Business Administration, The University of British Columbia, March 1991.

40. Winston M. E., Chaffin R., Herrmann D.: "A Taxonomy of Part-Whole Relations"; Cognilive Science, Vol.11, 417-444, 1987. 


\section{Appendix}

Examples to demonstrate the transitivity of arbitrary two-place variations of the corc part-of catcgorics:

component/objcet portion/mass place/area

1) component/object and portion/mass

variable part-of statement,

statcment part-ol code

$\rightarrow$ variable part-of code;

3) component/object and place/area

$\mathrm{CN}$-Tower part-of Toronto;

Toronto part-of Canada

--> CN-Tower part-of Canada;

5) portion/mass and place/area

South of Everglades part-of Everglades, Evcrglades pat-of Florida

--> South of Evcrglades part-ol Florida;
2) portion/mass and component/object

statement part-ol code, code part-of soltware product

--> slatcment part-of softwarc product;

4) place/arca and component/object

Toronto part-of Canada,

Canada part-of world

$\rightarrow$ Toronto part-ol world;

6) placc/arca and portion/mass

Toronto part-ol Canada, Canada part-of contincnt

--> Toronto part-of continent;

Example to demonstrate the transitivity of part-of relations belonging to the verbfcaturc/activity catcgory:

7) testing part-of implementing, implementing part-of developing software

--> Icsting part of devcloping soltwarc. 